\title{
EL CONCEPTO DE CATARSIS EN LA ESTÉTICA DE LUIS JUAN GUERRERO
}

Yanina Benítez Ocampo Instituto de Filosofía Ezequiel de Olaso (CONICET) Universidad Nacional de San Martín

DOI: $10.36446 /$ be. 2020.52 .222

\section{Resumen}

El tratamiento que realiza Luis Juan Guerrero (1899-1957) sobre la noción de catarsis en el primer tomo de Estética operatoria en sus tres direcciones (1956), es mucho más importante para su teoría estética de lo que aparenta. A partir de una crítica a las teorías tradicionales de la contemplación y un análisis de la influencia subjetiva de las obras de arte, nos aporta un marco teórico alternativo para la comprensión de dicha noción.

\section{Palabras clave}

Estética Argentina; Experiencia Estética; Contemplación; Efectos Subjetivos; Autotransformación

\section{The concept of catharsis in the Aesthetics of Luis Juan Guerrero}

\section{Abstract}

Luis Juan Guerrero's (1899-1957) treatment of the notion of catharsis in the first volume of Estética operatoria en sus tres direcciones (1956) is much more significant for his aesthetic theory than it appears. Starting from a critique of the traditional theories of contemplation and an analysis of the subjective influence of artworks, it gives us an alternative theoretical framework for understanding this notion.

\section{Keywords}

Argentinean Aesthetics; Aesthetic Experience; Contemplation; Subjective Effects; Self-transformation

Recibido: 17/06/20. Aprobado: 11/09/20. 
En el primer tomo de Estética operatoria en sus tres direcciones (1956), Luis Juan Guerrero no desarrolla un tratamiento pormenorizado y sistemático sobre el concepto de "catarsis"; sin embargo, nos ofrece una exposición cuya línea de análisis deriva en la observación de dicho concepto. En principio, este abordaje aparenta ser tomado en el marco de una ordenación argumentativa secundaria, pero posteriormente revela un valor conclusivo sumamente importante para su obra y más allá de ella. A fin de alcanzar una comprensión adecuada de sus exposiciones al respecto, además de las teorizaciones explícitas, es preciso observar algunos pasajes de su obra donde no alude directamente al concepto de catarsis pero desarrolla contenidos claramente relacionados con él. En el presente artículo nos proponemos analizar este tratamiento que si bien puede prestarse a cierta confusión por el modo en que nos lo presenta su autor, en verdad sugiere una interpretación alternativa sobre la noción en cuestión.

\section{CRÍTICAS DE LAS TEORÍAS TRADICIONALES DE LA CONTEMPLACIÓN ESTÉTICA}

En su Estética operatoria Guerrero analiza nuestro trato con las obras de arte. Para su abordaje, parte de un análisis sobre la orientación de nuestros comportamientos frente a las obras; es decir, estudia los diversos modos y niveles existenciales puestos en juego en la experiencia estética. ${ }^{1}$ Cada comportamiento constituye una dirección estética, entendida como una modalidad de apertura del ser humano frente a la obra de arte. Las direcciones, como tales, no se fundan en la relación clásica entre objeto y sujeto sino en las modalidades de apertura del ente, por lo que no deben ser confundidas con aspectos diversos de la conciencia; tampoco se las puede considerar como estados diversos del conocimiento, sino más bien como un encuentro y una con-cordancia entre dos existentes (véase Guerrero 2008: 167). ${ }^{2}$

Guerrero desarrolla su propuesta a la par de una exposición crítica sobre las teorías tradicionales de la contemplación estética. ${ }^{3}$ Según

\footnotetext{
${ }^{1}$ Estos niveles existenciales no deben ser confundidos con tres episodios diferentes de un mismo hecho. Guerrero distinguirá tres tipos de comportamientos o actitudes del ser humano frente a las obras de arte: 1) una actitud referida al Ser (revelación y acogimiento), 2) otra a la Esencia o Potencia (creación y ejecución) y, finalmente, 3) otra referida a la Tarea (promoción y requerimiento). Véanse los parágrafos 1 y 2 del capítulo "Triple dirección de los comportamientos estéticos" (Guerrero 2008: 165-168), donde se definen las orientaciones que serán explicadas en el desarrollo del estudio. Desde esta perspectiva, la estética es presentada como "una analítica trascendental de los tres comportamientos fundamentales del hombre hacia las obras de arte" (Ibarlucía 2008: 64).

${ }^{2}$ Citamos la edición a cargo de Ricardo Ibarlucía (Guerrero 2008), a cuya autoría corresponde también el estudio preliminar y el apéndice bibliográfico que complementan la obra. Según Ibarlucía, Guerrero "busca superar de este modo la unilateralidad de las doctrinas que interpretan primordialmente la experiencia estética como 'goce' exquisito, 'descarga' de emociones o 'expresión' de vivencias íntimas como la de aquellas que reducen el arte a 'imitación' o 'idealización' de la realidad. $\mathrm{El}$ arte, piensa Guerrero, no es una variedad del conocimiento teórico ni la manifestación de fuerzas irracionales o divinas, ni el 'reflejo' mecánico de intereses sociales, 'sino el más fundamental acontecer histórico de la sensibilidad humana"” (Ibarlucía 2008: 65).

${ }^{3}$ En lo que sigue, nos ceñimos a los aspectos de la crítica guerreriana en estricta relación con el estudio del fenómeno de la catarsis, haciendo hincapié principalmente en el primer tomo de la Estética.
} 
su interpretación, dichas teorías consideraron tan solo un aspecto de la experiencia en cuestión, es decir, sus reflexiones se redujeron al análisis del momento de la contemplación, a la que adscribían la totalidad de la experiencia estética. ${ }^{4}$ Dos de los términos principales -de elaboración conceptual propia- que estructuran su análisis sobre la experiencia estética son los de presencia y llamado, ambos concebidos como modalidades de apertura del ser de la obra. La presencia es entendida como una fuerza propia de ex-posición: "Presencia dice que la obra es capaz de mostrarse por sí misma, que tiene el poder de auto-exhibición y aun de auto-imposición" (Guerrero 2008: 206). Su modo de ser no equivale a un mero estar ahí, a un existente sin más, sino que refiere precisamente a ese complejo significativo o fondo de sentido que "compone(n) la totalidad de la obra". La presencia, entonces, es un conjunto de factores significativos de lo presente y ausente de la obra. El llamado por su parte es la interpelación consecuente:

Llamado dice la presencia irradiante y dirigida de una obra de arte, consignada y destinada a un contemplador y que, de tal manera, provoca la respuesta adecuada. Por eso, en esta escena, la revelación de la obra es el llamado que nos hace una presencia; y el acogimiento de la misma es la respuesta adecuada a esa acción de presencia: es la total sensibilización del contemplador para apreciar estéticamente la obra. (Guerrero 2008: 220, el resaltado es nuestro)

El ser humano, atento a esta apertura del ser de la obra de arte, asume las actitudes de acogimiento y revelación, entendidas como

${ }^{4}$ Guerrero destaca que la concepción de contemplación tradicional no será considerada ya como la única legítima "porque se sabe una abstracción ideativa de otros dos comportamientos -de creación-ejecución y de promoción-requerimiento-" (2008: 203). Es decir, representa apenas una parte de una experiencia mucho más compleja. modalidades de trato con la obra. "El acogimiento artístico -aclara Guerrero- es la realización de un encuentro entre ciertas posibilidades que brinda la obra misma y otras que alberga la existencia humana" (2008: 230). En otras palabras, "es la total sensibilización del contemplador para apreciar estéticamente la obra” (2008: 220). Por su parte, la revelación hace alusión al hecho de que, con respecto a la obra, "no somos los simples remitentes, sino los encargados de revelarla" (2008: 221). Ambas actitudes refieren a un estado de atención que no se equipara a la noción de contemplación propia de la tradición estética, en tanto dicha atención acentúa la dimensión de apertura del ser del individuo frente a la obra de arte. La experiencia estética, desde esta perspectiva, se nos presenta como una apertura de carácter existencial que se expresa en una vinculación real. ${ }^{5}$

La primera parte de la Estética está destinada al estudio de dichas actitudes. ${ }^{6}$ En el parágrafo 15 del capítulo dedicado, precisamente, a la noción de llamado, ${ }^{7}$ encontramos la primera de las tres menciones directas sobre la noción de catarsis en su obra, ${ }^{8}$ aunque el comentario es más bien ambiguo. Allí Guerrero alude a las teorías tradicionales de la contemplación, considerando a la catarsis como

\footnotetext{
${ }^{5}$ Por real aludimos al carácter mencionado.

${ }^{6}$ Cada una de ellas incluye diferentes escenas, es decir, contextos de sentidos. Guerrero define la escena como: "[un] complejo escénico [que] nos remite a un contexto de sentido, que suelda sus propios factores internos, pero dejando los fenómenos siempre abiertos hacia nuevas escenas, siempre in-terminados, como la vida misma" (2008: 194). Las cuatro escenas se reiteran en cada una de las orientaciones o direcciones estéticas, matizadas según el comportamiento propio de cada orientación.

${ }^{7}$ Se trata del segundo parágrafo del capítulo "Llamado", perteneciente a la "Escena de entonación” (véase Guerrero 2008: 223-224). La noción de llamado aparece alli definida como: "la cumplida entonación de una presencia".

${ }^{8}$ Para constatar las otras menciones, véase Guerrero 2008: 223, 224 y 238.
} 
la más antigua y difundida de ellas. La referencia es muy general, tan solo nos explica que en el marco de la tradición la obra de arte fue reducida a una presencia objetivada, cuyo efecto se explica tan solo por su impacto sobre la subjetividad de un espectador pasivo.

El término en cuestión es introducido como parte de una síntesis histórica sobre las tematizaciones referidas a la influencia de la obra de arte sobre el ser humano, lo que a su vez constituye una línea argumentativa para demostrar el reduccionismo que generalmente se ha operado sobre lo que el autor considera una de las nociones clave para la comprensión de la experiencia estética, a saber: llamado -alude al fenómeno involucrado en él, aunque no haya sido denominado bajo dicho término en otros momentos de la historia. En la síntesis que nos presenta, podemos advertir la crítica a dos grandes dominios teóricos: una línea clásica arraigada en la perspectiva de la antigüedad griega y, en general, afín al realismo filosófico; y el conjunto de teorías vivenciales o subjetivistas.

La interpretación que nos ofrece del pensamiento clásico antiguo es muy escueta, y aunque luego haga mención de la catarsis aristotélica, carecemos de una exposición precisa al respecto, solo afirma que se trata de una de las nociones que más ha gozado de difusión y reapropiación en la historia de la filosofía. Expresado de un modo sintético, inferimos por su postura general que las objeciones de Guerrero van dirigidas contra las interpretaciones realistas de la antigüedad griega, aplicadas aquí al campo de la estética. Este hecho, habría suscitado el surgimiento de una serie de interpretaciones muy variadas entre sí, especialmente durante la modernidad, que a su vez han tendido a reducir a la catarsis aristotélica a una mera cualidad añadida a la nota de presencia de la obra, es decir, a tratarla como a "un agregado extra-estético, cargado de ambigüe- dades (interpretaciones moralistas, hedonistas, patológicas y tantas otras)" (2008: 223).

$\mathrm{Al}$ referirse a la recepción de la noción de catarsis realizada por la modernidad, a pesar de ser expuesto a modo de un simple comentario, Guerrero utiliza la expresión: "la tan maltratada catarsis" (2008: 223), con ello, como expusimos más arriba, pretende señalar las distorsiones teóricas graves que sufrió dicha noción a lo largo de la historia. Este comentario también sugiere que, si bien cuestiona la noción de cuño aristotélico, su crítica se incardina especialmente en propuestas de los autores modernos. Advierte en estos pensadores un desorden teórico que vuelve más problemático el análisis de lo que de por sí ya le resulta cuestionable de la antigüedad, al punto de considerar que en ese abanico sin fin de matices y variantes se ha llegado a perder todas las referencias conceptuales del término catarsis.

Esta crítica no se restringe a dichos pensadores, sino que se extiende hacia la contemporaneidad; específicamente, apunta contra el psicologismo positivista del siglo XIX, que retoma algunos presupuestos de la Estética sentimental del siglo XVIII -Diderot, Burke-, la teoría de la simpatía estética o Einfühlung -menciona la contribución de Herder y los románticos y la recepción de Vischer, Volkelt y Lipps-; también hace mención a las teorías de la promoción existencial -Souriau- y al temple de ánimo o Stimmung de Heidegger, Kaufmann y Pfeiffer. A todas estas teorías les imputa el haber quedado atrapadas, de un modo u otro, en el marco de sus propias concepciones fundadas en la subjetividad. 


\section{EFECTOS SUBJETIVOS DE LA OBRA DE ARTE}

Guerrero se propone demostrar que las interpretaciones sobre la influencia subjetiva de la obra de arte -tema que vertebra el apartado titulado "Llamado" (véase 2008: 220-238) -, si en algunas ocasiones se han estructurado sobre el concepto de catarsis, en otras lo han hecho sobre las denominadas teorías sentimentales o emotivas -“conmoción del alma, desequilibrio vital, etc.” (2008: 223) -; pero haya sido de un modo u otro, buscaron explicar siempre el mismo fenómeno.

En los parágrafos 16, 17 y 18 del mencionado apartado, encontraremos un análisis pormenorizado sobre el efecto subjetivo de las obras de arte; sin embargo, una vez más, la cuestión de la catarsis no se presenta expuesta por sí misma sino en orden a una crítica a las teorías vivenciales o subjetivistas de la experiencia estética. ${ }^{9}$ Sobre ellas, Guerrero destaca dos puntos sobresalientes que parecen verificarse en el curso de todas las teorías que se han aglutinado bajo esta perspectiva:

$1^{\text {a }}$ - Las tentativas, casi siempre fracasadas, de elevación de la existencia humana hacia esferas que trascienden la vida cotidiana y el mundo circundante.

$2^{\text {a }}$ - La prevalencia de un temple o disposición irrealizantes ${ }^{10}$ que vuelve enteramente ambiguos todos esos escolares procedimientos 'catárticos'. (Guerrero 2008: 229)

\footnotetext{
${ }^{9}$ En rigor, el tema se encuentra inserto en el análisis sobre las teorías que Guerrero considera como la encrucijada de los problemas estéticos que le son contemporáneos, a saber: las teorías que reducen el llamado a una captación vivencial y la libre actualización de la obra de arte (véase 2008: 223-224).

${ }^{10}$ Sobre el carácter irrealizante trataremos más adelante, baste aquí con observar su relación de contrariedad con la vida real o cotidiana en el marco de la experiencia estética.
}

De estos puntos podemos observar, por un lado, el señalamiento de un presupuesto general y recurrente en la historia de la estética filosófica según el cual la experiencia frente a la obra de arte produciría una elevación del ser humano sobre su condición, proceso expresado en una suerte de aislamiento del mundo provocado por la influencia de la obra, cuyos efectos, además, contribuirían a mejorar su estado anímico. Guerrero concluye en que la mayor parte de las tentativas en dicho sentido han fracasado debido a que se han montado sobre lecturas fragmentarias o bien atomizadas de la experiencia en cuestión. Por otro lado, al supuesto estado de elevación consecuente a la experiencia estética, opone una disposición anímica que considera fundamental para la concreción de dicha experiencia. Es decir, según Guerrero, la existencia de estas disposiciones pondría en entredicho los términos de aquel supuesto, entre ellos, los de la catarsis en su concepción tradicional, como veremos más abajo.

En las discusiones sobre estos aspectos, Guerrero precisa que el recurso a las teorías vivenciales o subjetivistas, en la mayoría de los casos, ha contribuido a la simplificación de campos teóricos, como ha sucedido con la reducción de las nociones de catarsis y temple heideggeriano a una especie de subjetividad pasiva (véase 2008: 223-224).

A partir de su exposición general, podemos presumir, en principio, que Guerrero no rechaza taxativamente la noción de catarsis, sino que objeta su estatuto dentro de un tipo de concepción general sobre nuestra relación con la obra, según la cual la catarsis quedaría subsumida a una suerte de proceso de enajenación. Es cierto que no poseemos una referencia precisa sobre su postura frente a la concepción de catarsis aristotélica, pero en los pasajes que hemos mencionado su crítica se inclina hacia las recepciones modernas de di- 
cha noción; con esto no presuponemos que se abstenga de toda crítica a la concepción aristotélica, pero sí que su cuestionamiento parece ejercerse con menor fuerza que con respecto a sus reelaboraciones posteriores. No obstante, como mencionamos, no desarrolla esta cuestión, tan solo nos la presenta como un apéndice del análisis de las teorías vivenciales.

Ahora bien, al presentar su crítica sobre las teorías que explican la relación estética a partir de una proyección sentimental, aborda una cuestión esencial para las diferentes interpretaciones sobre la catarsis, a saber: la discusión sobre el sentido o carácter durativo de los efectos de la obra sobre el sujeto. Recordemos que este aspecto, en el marco de los análisis de la antigüedad griega, sigue sujeto a debate; $;^{11}$ la falta de acuerdo radica fundamentalmente en el valor moral que se le adjudica a dicho concepto, es decir, la consideración acerca de si sus efectos van más allá o no de la experiencia frente a la obra de arte $y$, por supuesto, si implican alguna transformación en el ser humano y, de ser así, de qué tipo se trataría ésta. Guerrero niega la posibilidad de que la denominada proyección sentimental empatía- emparente al espectador directamente con el artista y, por lo que sugiere en su texto, tampoco admite algún tipo de proyección sentimental sobre la obra -por tratarse de una forma unilateral de relación estética. En cambio, admite provisoriamente en su ar-

\footnotetext{
${ }^{11}$ El estatuto de la catarsis aristotélica sigue siendo controversial. Leon Golden afirma que pueden señalarse tres grandes posturas al respecto: (1) Una forma de purificación moral; (2) un elemento de la estructura de la trama; (3) una suerte de clarificación intelectual (véase Golden 1962). Cabe aclarar, por un lado, que en el caso de (1) se plantean diferencias entre quienes prefieren expresarse en términos de purgación (noción ligada a aspectos más bien del orden fisiológico y pulsional) y quienes lo hacen en términos de purificación (noción ligada más a aspectos morales); por otro lado, que es posible agregar una postura más, aquella que relaciona la catarsis con efectos psicagógicos (véase Halliwell 2003).
}

gumentación que la obra "nos pro-pone, ayuda y hasta obliga a adoptar una nueva actitud ante el mundo y las cosas" (2008: 225, el resaltado es nuestro). Esta nueva actitud, que solo en un orden secundario nos puede aproximar al artista, implica un distanciamiento con respecto a la vida cotidiana y, de algún modo, nos transporta a otro plano de la vida en general, un fenómeno que comúnmente se ha considerado como una suerte de elevación sobre uno mismo.

Según Guerrero, esta interpretación, cuya aceptación por parte de los estudiosos contó con un amplio alcance a lo largo de la historia, ha tenido tratamiento dentro de dos grandes concepciones: una que propugna un cambio real en el sujeto y otra que asume un cambio adoptivo en la postura o actitud vital de aquel. En el caso de la primera, la influencia ejercida por la obra de arte sobre el ser humano produciría una transformación durativa en el carácter o postura empírica, ${ }^{12}$ por lo tanto, se trataría de un cambio real. En el caso de la segunda, dicha influencia produciría un cambio temporal, cuyo lapso se extendería a la experiencia frente a la obra; durante ese intervalo, nuestro carácter empírico adoptaría una postura diferente. Una experiencia de esta índole implica la adopción temporal de una postura que nos llevaría a superar las convenciones y, merced a ello, a conferirle a nuestras vidas ciertos caracteres de nobleza y purificación:

Si nos sentimos sobreelevados por imperio del arte, si nos sentimos como transportados a otro plano de vida, es porque la obra nos ayuda a elevarnos por encima de nuestra vida real. [...] En otras palabras, si en la vida cotidiana vemos las cosas con un criterio estrecho y vulgar, a través de conveniencias, convenciones, etc., la obra de arte nos obliga a

${ }^{12}$ Podemos considerar al carácter o postura empírica como al conjunto de cualidades y reacciones corrientes o habituales de cualquier ser humano. 
adoptar, en cambio, una actitud que supera esos convencionalismos. Así llegamos a darle a nuestra existencia otros contenidos de pureza, de generosidad de refinamiento superior, con respecto a los que realizamos en nuestro ámbito cotidiano. (Guerrero 2008: 225-226)

En principio, como señalamos más arriba, Guerrero parece adscribir a la segunda de las concepciones. No obstante, sus afirmaciones no son conclusivas y obedecen a un orden metodológico particular. Recordemos que previamente introduce esta cuestión para afirmar nuestra relación directa con la obra, negando así toda proyección hacia el artista y llevando a cabo un examen sobre "Nuestra participación en la obra de arte" (título del parágrafo 16). De allí proviene el énfasis puesto en la sobreelevación que provocaría nuestra experiencia frente a la obra. Ahora bien, en el parágrafo 17, Guerrero se interroga precisamente sobre "La participación de la obra de arte en nuestra existencia" (título del mencionado apartado), donde precisa su idea acerca de dicha sobre-elevación, la cual, además de establecerse con la obra y no con el artista, dura solo el intervalo en que se produce tal relación. Señalemos que, hasta aquí, este poder que ejerce la obra sobre nuestra existencia no es concebido como real sino como adoptivo, un punto que será central para las explicaciones posteriores.

\section{REAL E IRREAL}

Guerrero se propone demostrar, en principio y de manera parcial, que todos aquellos valores morales que han entrado desde antiguo en la discusión sobre la durabilidad de la influencia que ejerce la obra de arte y el tipo de efecto que provoca en el individuo no radican verdaderamente en una postura real sino en una postura adoptiva. La oposición entre una postura real y una postura adoptiva se establece se- gún la remisión al orden de lo cotidiano y se puede traducir como una oposición entre vida cotidiana y experiencia estética:

No proviene de nuestra experiencia cotidiana (la postura adoptiva), ni está fundada en razonamientos o decisiones de nuestra vida real, sino que es simplemente "inventada" durante ese intervalo en que convivimos con la obra de arte, aunque, desde luego, en ese intervalo puede ser tan fuerte como para pretender apoderarse de toda nuestra existencia. (Guerrero 2008: 226) ${ }^{13}$

Desde esta perspectiva, la obra de arte nos obliga a adoptar una nueva postura frente a ella, acorde a su existencia, en cuyo caso podemos llegar a sentir que rebasa nuestro orden existencial y nos trasporta a un nivel más elevado $\mathrm{y}$, de algún modo, más puro y noble. Esta experiencia, entonces, rompe con el orden de la vida cotidiana y solo en este sentido debe entenderse como una ruptura con lo real. ${ }^{14}$

La idea corriente de que el arte purifica o ennoblece es propia de las doctrinas que reducen el llamado de la obra a una mera apelación subjetiva -podemos ubicar también en esta posición a la concepción antigua de la catarsis. En dicha lectura, la purificación moral a través de la obra de arte, mediante ciertos valores como la generosi-

${ }^{13}$ El uso del término "real” por parte de Guerrero puede suscitar ciertas confusiones con respecto a los niveles empírico y existencial y las modalidades subjetivas o posturas del yo real y el yo irreal. En este caso, se circunscriben al tipo de cambio de postura en o a partir de la experiencia estética; en los casos en que se remita a una oposición entre yo real y yo irreal, seguirá la diferenciación establecida por Jean-Paul Sartre en Lo imaginario.

${ }^{14}$ La oposición se establecería en verdad entre vida cotidiana/ vida real y experiencia estética/ vida irreal. El concepto de lo adoptivo quedaría enmarcado en ésta última. 
dad o la benevolencia, suscitados por la experiencia estética, eliminaría las impurezas y, consecuentemente, provocaría cierta pureza anímica en el alma del espectador.

Guerrero observa que en estas teorías subyace una falta de distinción entre una postura real y una postura adoptiva, ya que suponen, sin mayor examen, fundarse en una postura real cuando su posición, en consecuencia, con sus premisas, solo puede ser adoptiva y durar un cierto tiempo, el del intervalo en que la obra nos afecta. Así pues, si la experiencia estética realmente nos purificara, entonces su valor durativo -puesto que la purificación representa un cambio real y, por lo tanto, como tal debe ser durativo- pasaría a implicar la adquisición de una nueva postura real. Esto implicaría, a su vez, aceptar que es posible pasar de una postura real a otra postura real sin mediación de ningún tipo.

Sin embargo, según Guerrero, puesto que está claro que el punto de partida de estas teorías, muy a pesar de ellas, no es una postura real -procedente de nuestra vida cotidiana-, ya que se trata del caso de una experiencia estética -una experiencia que de suyo involucra una postura irreal-, el efecto de la obra de arte sobre nosotros no podría producir ninguna valoración específica, puesto que no se estaría tratando con valores "reales" -cotidianos-, sino tan solo adoptivos: ¿cómo podría una postura adoptiva, sin ningún arraigo vital, producir valores que son reales? Así pues, adoptaríamos por cierto tiempo determinados valores porque conllevarían el mismo significado que en la vida "real", pero "no por ello nos hemos vuelto ni más puros, ni más generosos, ni más profundos" (Guerrero 2008: 226). Las teorías vivenciales, entonces, tratan sobre cambios en la esfera del carácter empírico y no en la esfera existencial, ya que no es posible ningún cambio desde una postura real a otra sin mediación en el marco de la experiencia estética.
Hechas estas aclaraciones, debemos notar que Guerrero no rechaza todos los aspectos de la interpretación adoptiva, pero afirma que la misma sería imposible sin la existencia de ciertas disposiciones previas que permitan realmente la elevación del alma. Las interpretaciones subjetivistas o vivenciales revelarían, en última instancia, una contradicción suscitada por la falta de distinción entre valores profundamente arraigados y valores inestables que solo existen en un plano empírico pero que, durante el tiempo en que persisten, parecieran ser lo suficientemente intensos como para que podamos confundirlos con valores "reales". Por lo tanto, para eludir esta vía errónea, a la fuerza que ejerce la obra de arte sobre el espectador debemos considerar que le corresponde cierta disposición anímica o "simpatía afectiva" por parte del individuo (véase Guerrero 2008: 227). Por ejemplo, debe existir en nosotros la disposición a la generosidad de manera latente para que la obra pueda suscitarla realmente, tal como otro tipo de cualidades que son posibles porque no se contraponen a nuestra postura real o cotidiana. Las obras de arte, entonces, despiertan valores positivos ya latentes en nosotros que, al actualizarse, nos elevan por sobre nuestra condición corriente:

Este es entonces el punto decisivo para juzgar la "influencia anímica" de las tituladas "vivencias estéticas". Ellas producen, por cierto, una transformación de nuestra conducta cotidiana. El significado de nuestra existencia se eleva por encima de sí misma. Nuestra vida entra en dominios vedados a la realidad corriente. En suma, esa "influencia" permite y hasta provoca el despertar de ciertos estratos existenciales que dormían en el trajín de todos los días. (Guerrero 2008: 227)

Con esta interpretación, Guerrero cree haber demostrado el error de las posturas tradicionales, que pretenden afirmarse sobre posturas reales cuando, en verdad, el resorte que les permite funcionar no se encuentra en un cambio del carácter empírico sino en la maleabi- 
lidad del mismo, la misma maleabilidad que permite adoptar una postura nueva y que, como tal, supone la latencia de los valores que moldea. Dicho carácter empírico, entonces, debe ser maleable para poder recibir la influencia de la obra:

[...] quien es pequeño, vulgar o mezquino en su carácter empírico, no puede comprender ese tipo de obras de arte. Quien está encerrado en convenciones y prejuicios, no puede poseer una disposición o temple anímico que le permita elevar su vida por encima de ella misma. Más aún: quien está encerrado en virtudes demasiado rigurosas o en costumbres puritanas, quien tiene un carácter demasiado seco y severo, no puede poseer la maleabilidad necesaria para elevar la propia existencia sobre su nivel común. (Guerrero 2008: 229)

La maleabilidad, desde este punto de vista, es fundamental para que se establezca nuestra relación con la obra de arte. La influencia que recibimos de ésta nos eleva por sobre nuestra conducta habitual porque preexiste en nosotros esa capacidad -o disposición-, una especie de apertura a la auto-trascendencia. Por lo tanto, alcanzar un cambio en la conducta empírica, en lo habitual, sin el resorte de la maleabilidad, implicaría aceptar que los cambios de posturas son reales -en el sentido de que se darían directamente en la postura de vida cotidiana- y que se pueden establecer sin ninguna disposición previa, además de ser determinantes en tanto el sujeto sería un mero receptor pasivo del efecto de las obras de arte. La maleabilidad, entonces, es el concepto que permite estructurar la concepción de un cambio posible aunque no necesario de la postura o conducta habitual, en la medida en que tales cambios serían, en primera instancia, adoptivos.

Sin embargo, la clave para interpretar el influjo de la obra de arte, según Guerrero y a diferencia de las posturas anteriores, se halla en la libertad. La noción de libertad será el término bisagra para desmontar las teorías tradicionales y proponer la suya, por lo que se intenta demostrar que la implicación del acogimiento en el llamado de la obra nos conduce a plantearnos el alcance de la libertad humana en la experiencia estética:

Ellas (las doctrinas vivenciales) olvidan que el acogimiento artístico es la realización de un encuentro entre ciertas posibilidades que brinda la obra misma y otras que alberga la existencia humana. Y por añadidura, que además de estas abstractas posibilidades, se necesita un lugar propicio, un clima favorable para ese encuentro. (Guerrero 2008: 230)

El acogimiento, según Guerrero, es el vínculo entre el ser humano y la obra de arte, es decir, una relación que requiere de igual modo de ambas partes para su realización, como así también son necesarios los factores adecuados desde el punto de vista socio-histórico.

\section{MALEABILIDAD Y LIBERTAD}

Hasta aquí hemos dado repaso al modo en que las teorías tradicionales se fundamentan en una postura adoptiva -muy a pesar de sus exposiciones al respecto- y cómo, en consecuencia, el resorte que las hace funcionar es la maleabilidad del carácter empírico. Luego de clarificar la estructura de estas teorías, Guerrero amplía su crítica pasando a cuestionar el estatuto de la maleabilidad como verdadero resorte que posibilite el influjo sobre el sujeto. Dicho resorte solo puede ajustarse a una postura o actitud adoptiva y, siendo así, revela la imposibilidad de un arraigo existencial de los efectos de la obra de arte en el ser humano, al menos bajo tal esquema interpretativo. De allí la provisionalidad de sus proposiciones, que aparentan en un 
primer momento consentir con una postura adoptiva, pero en verdad las está orientando hacia una crítica sobre ella.

En el parágrafo 18 del apartado titulado "Llamado", Guerrero nos anticipa que para poder realizar un análisis preciso sobre la posibilidad de una elevación mediada por el arte es menester excluir aquellas obras fundadas en valores imitativos, ${ }^{15}$ que "tienden a una simple reproducción", y en valores formales de euritmia, "que tienden más bien a un puro sentido ornamental del arte" (2008: 228). ${ }^{16}$ En el parágrafo 24, dedicado a las pasiones, la catarsis y la posibilidad de "auto-transformación" del ser humano, agrega a las posturas objetadas aquellas obras de arte que apelan al sentimentalismo frecuentemente denominadas "pasionales"- a través de "recursos mórbidos", es decir, aquellas que exacerban las pasiones y que, por lo tanto, se mantienen en un nivel de superficialidad que reduce la participación del individuo a un estado de completa pasividad. En dicho estado, el ser humano pierde su capacidad de reacción espontánea y libre pues, aunque la obra pueda alcanzar cierta dimensión más o menos profunda de nuestra existencia, se nos impone de tal forma que no podemos más que aceptar su presencia. En un sentido opuesto, critica aquellas obras cuyo tema o tesis nos resulta fácilmente inteligible, pues esa condición puede tornar el tema fácilmente en un contenido extra-estético, dejando de afectarnos como parte integral de la obra misma para pasar a ser un mero contenido intelectual.

\footnotetext{
${ }^{15}$ Entendemos que el sentido mimético al que refiere Guerrero, ligado a la mera reproducción, no es taxativo con respecto a su interpretación de dicho concepto, sino meramente incidental, es decir, ajustado a una crítica de ese tipo de producciones del arte de contenidos y formas superficiales.

${ }^{16}$ La observación radica aquí en el mayor rigor de análisis que se adquiere al observar obras que por sí mismas apunten a valores de elevación o superación.
}

En este punto, la distinción sartreana entre imperativo hipotético e imperativo categórico aplicada a los útiles y las obras de arte ${ }^{17}$ respectivamente, es introducida por Guerrero para arribar a la conclusión de éste capítulo. ${ }^{18}$ Se ocupa de distinguir, por un lado, que el imperativo hipotético no apela a nuestra libertad -aunque se sirva de ella-, en tanto que los útiles son instrumentos que ayudan a la consecución de determinados fines; y por otro, que el imperativo categórico no solo apela sino que moviliza nuestra libertad. Esto significa que su influencia es de una intensidad tal que nuestra libertad se ve instada a responder, aunque el tipo de respuesta dependerá de su propia resolución. En este sentido, es más que elocuente señalar algunos requerimientos generales que nos presenta Guerrero:

Comienza por exigirnos que realicemos un acto; por de pronto, el acto de hacernos cargo de la obra: de 'atender' a este cuadro o a esta sinfonía, de leer aquella novela, etc. Y al penetrar en tales obras, el acto de comprenderlas en su índole más específica, de escuchar el llamado que nos formulan. Es decir, en el fondo, recrearlas, volverlas a constituir, hacer que no solo existan virtualmente, fuera de nosotros, sino que se conviertan actualmente, por nosotros, en obras de arte. (Guerrero 2008: 234, el resaltado es nuestro)

La experiencia estética, como podemos apreciar, es concebida aquí como una relación cuyos términos tienen un valor individual y recíproco, y un carácter equitativo en la conformación de la dinámica que los vincula. Guerrero ilustra este evento con la imagen de

\footnotetext{
${ }^{17}$ Aquí recurre a la distinción entre lo "útil” y la "obra de arte" acuñada por Heidegger (1935).

${ }^{18}$ Guerrero preferirá luego ceñirse al término sartreano equivalente para señalar este aspecto, a saber: "valor" (véase Guerrero 2008: 237).
} 
un "pacto" ${ }^{19}$ Nuestra actitud frente a la obra de arte, entonces, es la de quien libremente acepta relacionarse con ella -en este sentido, es interesante observar que distingue esta actitud de la de un espectador que solo constata la presencia de una obra de arte-, así como adaptarse a sus exigencias y, en ese mismo acto, recrearla. A su vez, recordemos que la obra debe cumplir con los requerimientos histórico-sociales en los que se enmarca para poder ser comprendida, por lo tanto, su creación no es aislada, sino puesta desde el comienzo en una dinámica de vinculación que apela a ciertas dimensiones humanas.

Desde esta perspectiva, una obra de arte puede considerarse auténtica en la medida en que nuestra capacidad de recepción a su influencia sea libre. De igual modo es el efecto sobre nuestras pasiones. Las mismas deben ser libres en lugar de presentársenos como reacciones o respuestas ineludibles a la obra, debemos poder sentirlas "como resortes por medio de los cuales podemos disponer nuestra propia libertad" (Guerrero 2008: 238).

Ahora bien, si lo que se dispone es la libertad como respuesta al llamado de la obra, por lo tanto, la influencia de la obra no se explica estrictamente por la tesis de la maleabilidad del carácter, sino por un tipo de acogimiento de la obra cuyo alcance tiene un arraigo en nuestra existencia; es decir, cuyo carácter cualitativo alcanza un nivel existencial más profundo que la maleabilidad posible del carácter empírico. La maleabilidad, entonces, solo produce posturas adoptivas y, por lo mismo, temporales y desarraigadas. En cambio, una respuesta de arraigo existencial produce una postura real, a

\footnotetext{
${ }^{19}$ Guerrero entrevé en la postulación kantiana de la obra como una finalidad sin fin un equívoco que niega la dirección establecida del llamado, cuyos efectos motorizan nuestra libre decisión. Véase Guerrero: 151.
}

cuya experiencia se suscita o se puede suscitar una autotransformación existencial del ser humano que es llevada a cabo libremente por él: "Diremos, en cambio, que gracias a la fuerza de la obra para incitarnos a elaborar libremente una respuesta, ella puede ser una fuente de hondas transformaciones en la vida de los individuos, las épocas y los pueblos" (Guerrero 2008: 239).

Ésta es, pues, la tesis que Guerrero desea probar y cuya argumentación va dirigiendo a través de los parágrafos que hemos mencionado. No rechaza la maleabilidad -de allí que su posición en el parágrafo 18 pueda presentársenos con cierta ambigüedad-; por el contrario, la considera necesaria como condición para la experiencia estética, pues, como vimos, un carácter estrecho o ensimismado no poseería la necesaria disposición de ánimo para recibir a una obra de arte, la diferencia es que dicha experiencia no se reduce a la maleabilidad del carácter empírico. De hecho, si nos atenemos a que en las conclusiones de dicho parágrafo menciona que estas conforman una autocrítica y en los parágrafos siguientes tematiza el estatuto de la libertad en la influencia de la obra de arte, podemos convenir, sin lugar a duda, que debe existir cierta maleabilidad del carácter empírico, pues, de otro modo, no sería posible la recepción de la obra las interpretaciones quedarían encerradas una vez más en el paso de una postura real a otra postura real. Sin embargo, la bisagra que permite la relación dinámica entre la obra de arte y el ser humano es la libertad; pero no la libertad a secas, no una libertad unilateral como en las teorías tradicionales y las subjetivistas-, sino la libertad motorizada por el influjo de la obra.

Precisamente, llegados a este punto, Guerrero nos ofrece la pista más sólida que, a su vez, nos ha permitido inferir más arriba que su crítica a la catarsis en la Estética no es taxativa, sino ajustada a determinados aspectos y al estatuto que dicha noción ha adquirido en 
ciertos momentos históricos. En efecto, seguidamente a la cita anterior se pregunta: “¿Pero no es éste, por ventura, el sentido último de la catarsis?" Su respuesta, por supuesto, no es aclarativa pues, como hubo declarado desde el inicio de su obra, el análisis de las doctrinas tradicionales queda fuera del marco teórico de su estudio. Y nuestra presunción se fortalece más aún al cerrar este capítulo recordándonos que tanto la filosofía griega como la racionalista escolar guardan una concepción antropológica retrospectiva. ${ }^{20}$ Por lo tanto, dentro de un esquema teórico de tal tipo, resulta coherente comprender a la catarsis como un efecto de purificación: se purifica aquello que impide el despliegue de las posibilidades ínsitas en la phýsis de cada particular. Por el contrario, para una filosofía cuya concepción antropológica sea prospectiva ${ }^{21}$-comentario que el buen lector entiende como una declaración teórica-, la catarsis palabra que omite solo por una elisión producto de la construcción sintáctica en que resuelve la oración- significa "un procedimiento de auto-transformación existencial": se autotransforma aquello que no adviene por el despliegue de lo dado sino por su propia capacidad de proyectarse como un ser abierto (véase Guerrero 2008: 239). Así pues, éste es el sentido que Guerrero le confiere a una noción tan cara.

\footnotetext{
${ }^{20}$ El verso de Píndaro sintetiza de un modo bastante adecuado la perspectiva antropológica de la antigüedad griega: "Llega a ser quien eres". En ella, el ser humano es exhortado al despliegue del contenido virtual de todas las posibilidades ínsitas en su realidad particular. Así, estudiar los procesos que constituyen la vida de un hombre nos lleva a revisar "lo que ya es" desde su origen o phýsis, lo cual introduce una particular tónica de retroactividad a las consideraciones sobre la vida humana. ${ }^{21}$ Resulta evidente que una interpretación antropológica tal se deriva de la gran importancia que ha tenido el pensamiento de Heidegger en Guerrero.
}

\section{¿POR QUÉ AÚN LA CATARSIS?}

A la luz de los estudios de los especialistas en el área de la antigüedad griega, es comprometido sostener que la concepción de la catarsis aristotélica no implique algún tipo de autotransformación ni de disposiciones previas, así como pretender reducirla a un mero sentido purificador. ${ }^{22}$ Lamentablemente, no podemos profundizar en este sentido puesto que Guerrero mismo ha trazado criteriosamente su marco teórico y sus afirmaciones sobre la antigüedad griega no son decisivas en el orden de su argumentación. Diferente es el caso de las recepciones modernas sobre dicho concepto, cuyas matizaciones han contribuido a complejizar el sentido aristotélico al respecto y, como vimos, son debidamente analizadas. La discrepancia teórica de Guerrero, entonces, se atribuye al esquema filosófico interpretativo desde el cual se parte para fundamentar el concepto de catarsis; el suyo, como declara, es prospectivo en términos antropológicos.

De este modo, podemos otorgarle un nuevo sentido a las conclusiones del parágrafo 18 que analizamos más arriba, y en las cuales se destaca, ahora a la luz del análisis precedente, que si Guerrero considera que casi todas las tentativas de elevación humana han fracasado se debe a que las mismas no han considerado adecuadamente la importancia de la relación vincular o la dinámica de interrelación que configura la experiencia estética al momento de evaluar la influencia de la obra de arte sobre el individuo. En efecto, la ambigüedad que le imputa a ese tipo de catarsis, que considera es-

${ }^{22}$ Existe una explícita relación de la ética aristotélica con los estados afectivos y las propensiones melancólicas (EN VII, 14, 1154b 11-15; EN 1106b 16-17), aunque el enfoque ético que el Estagirita le reserva a estas cuestiones en Política (VIII, 5-8) varía de su tratamiento en Poética, lo que ha abonado en las dificultades de interpretación al respecto. Sobre melancolía, véase también Problemas (XXX, 1). 
colar, nos hace presumir que se refiere más a este error interpretativo que objeta, que a un rechazo de la catarsis por sí misma.

Así pues, si considera que el temple o cierta disposición irrealizante presenta mayor solidez interpretativa que otras lecturas sobre la catarsis -clásica y subjetivista-, se debe a que el temple, precisamente, es la capacidad del individuo de en-tonar o estar al mismo tono que la obra. Dicho de otro modo, es la respuesta a un llamado que realiza la obra, cuyo modo de ser responde a su vez a un requerimiento social. Como tal, su vínculo con aquella se dispone o eleva a un nuevo modo existencial, por lo tanto, el individuo nunca es un receptor más o menos pasivo de la obra, como si se tratara de un receptáculo que se irá llenando conforme a los influjos recibidos, ni se cierne exclusivamente a una postura adoptiva, libre, pero no lo suficientemente arraigada en términos existenciales; por el contrario, es parte de un canal que fluye y se aviva gracias a las dos fuentes que lo alimentan.

La influencia que ejerce la obra adquiere un significado existencial, a cuya revelación nuestra vida se eleva por sobre sí misma. Guerrero no afirma la existencia de ningún tipo de purificación o ennoblecimiento, sino una elevación de la condición humana sobre sí misma -teniendo en cuenta la condición anterior. Considera, entonces, que la experiencia estética puede surtir un efecto decisivo en la vida del individuo, gracias a cierta distancia que abre con respecto a lo cotidiano, distancia que a su vez configura un nuevo modo de relación con el mundo. El concepto de catarsis no solo forma parte de su Estética, sino que su estatuto juega un rol importante en ella; de allí que advierta en su exposición cuál es la perspectiva teórica a partir de la cual, y según su criterio, puede ser tenida como una noción verdaderamente justificable.

\section{REFERENCIAS}

ARIsTóteles (1988), Política, trad. de M. García Valdés (Madrid: Gredos). (2004), Problemas, trad. Ester Sánchez Millán (Madrid: Gredos). (2007), Ética Nicomaquea, trad. de Eduardo Sinnott (Buenos Aires: Colihue).

_ (2009), Poética, trad. de Eduardo Sinnott (Buenos Aires: Colihue).

Golden, L. (1962), "Catharsis", Transactions and Proceedings of the American Philological Association, 93: 51-60.

GUERRERO, Luis Juan (1956), Estética operatoria en sus tres direcciones, tomo I (Buenos Aires: Losada).

(2008), Estética operatoria en sus tres direcciones, estudio preliminar y apéndice bibliográfico de Ricardo Ibarlucía, tomo I (Buenos Aires: Biblioteca Nacional, UNSAM Edita, Las Cuarenta).

(2017), Qué es la belleza y otros ensayos, estudio preliminar y edición a cargo de Ricardo Ibarlucía (Buenos Aires: Biblos, col. Pasajes/Serie Mayor).

HeIDEgGER, Martin (1935), "Der Ursprung des Kunstwerkes”, en Heidegger (1950: 1-74).

(1950), Holzwege (Frankfurt am Main: Klostermann).

HALliwell, Stephen (2003), "La psychologie morale de la catarsis. Un essai de reconstruction", Les Études philosophiques, 4, "La Poétique d'Aristote: Lectures morales et politiques de la tragédie": 499-517.

IBARLUCÍA, Ricardo (2008), "Luis Juan Guerrero, el filósofo ignorado", en Guerrero (2008: 9-68).

SARTRE, Jean-Paul (1940), L'imaginaire. Psychologie phénoménologique de l'imagination (París: Gallimard).

_ ([1940] 2005), Lo imaginario; trad. de Manuel Lamana (Buenos Aires: Losada). 